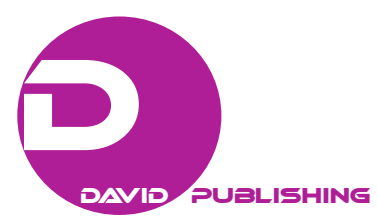

\title{
Large Family Card as an Instrument of Supporting Families With Many Children*
}

\author{
Anna Bebel \\ Wroclaw University of Economics, Wroclaw, Poland
}

\begin{abstract}
The aim of the article is to assess the efficacy of the large family card and its relevance to the real needs of families with many children, using the example of Poland. The large family card is a general term standing for locally implemented programmes that are aimed at families with many children. The idea behind the programme is to create a positive image of a large family. The very name of the programme serves the purpose of combating negative stereotypes and presenting large families as active and resourceful. The paper presents the results of empirical research conducted with cardholders and implementers of programs in selected Polish cities (questionnaire survey and focus group interviews with participants and interviews with program coordinators from 15 programs). Empirical research was conducted in the period from December 2013 to April 2014, and was funded by the National Science Centre. The study included all programs started by the end of 2011 . The conclusions enable a number of anomalies and weaknesses of the programs to be seen and indicate directions for further development of this promising initiative. The program is perceived very positively by large families, although it has little influence on family situation. Apart from its positive impact on the diversification of sports and recreation activities, it does not basically play any role in supporting the condition of the family. Neither healthcare nor the educational aspect is attractive enough to interest the family. The basic reason for the low quality of programs is primarily the lack of proper communication and knowledge about the real problems affecting large families.
\end{abstract}

keywords: family policy, large family card, large families, aging societies

\section{Introduction}

The article presents the large family card as a way of supporting families with at least three children. The idea behind the card is to create a positive image of a family with many children and to improve family living conditions, among others, by increasing access to monuments or sports/recreational facilities for large families. The program is addressed to all families with many children, regardless of their income. It foresees the issuing of cards entitling families to significant reductions or free admission to cultural sites, entertainment, or sports events as well as sometimes discounts or free travel by rail and public transport. The card's program also foresees discounts at selected stores.

The work includes empirical research. The study covered local large family cards in Poland and consisted

\footnotetext{
* Project Support: This research was funded by the National Science Centre in Poland and allocated on the basis of Decision No. DEC-2012/05/N/HS4/00219.

Anna Bebel, Master in Economics, Ph.D. Student, Wroclaw University of Economics, Wroclaw, Poland.

Correspondence concerning this article should be addressed to Anna Bebel, Wroclaw University of Economics, ul. Komandorska 118/120, Wroclaw, Poland. E-mail: anna.bebel@ue.wroc.pl.
} 
of a questionnaire survey among cardholders, interviews with program implementers, and focus group interviews (FGIs) conducted with program participants in selected cities. The questionnaire survey was conducted among families participating in programs. Due to the small number of participants in most programs it was possible to assume full study. Finally, more than 1,300 respondents from different cities took part in the survey. The survey was conducted by telephone as well as an online survey. The questionnaire consisted of 24 questions concerned assessment of the impact of various areas of life to its quality and questions concerning the card itself (e.g. card evaluation, the extent to which particular needs are satisfied, influence on family and social bonds). There were closed-ended and semi-open-ended questions. Some of the questions required that the respondents list answers in order of importance. The survey also included questions in the form of scales, e.g. a rating scale (which entails assigning ranks based on specified criteria) and the Likert scale (with a bipolar five-point intensity scale with categories described verbally) (Ostasiewicz, 2002). Questions concerning personal data pertained to, e.g., the number of children, income and the education of parents. The analysis and description of questionnaire results consisted mainly of the coding of the answers and statistical data analysis (e.g. determining statistical parameters such as the average, mode, and median).

An extension of the questionnaire survey was the FGIs which were conducted in selected cities with large family card holders. This study helped to develop a number of topics that appear in the questionnaire survey and to thoroughly analyze the specific situation of families with many children. Interviews with the implementers of the programmes, in turn, provided detailed information about the programmes themselves (which are not available in the programme documents and on the programmes' websites), e.g. about the premises and initiators of the programmes, their aims, methods of implementation and evaluations of the programmes, the number and structure of their beneficiaries as well as information concerning costs and directions of development of the programmes. A total of six focus groups and interviews with 15 coordinators of individual programs were conducted.

The role, situation, and support for families with many children will be presented, followed by a description of cards functioning in selected European countries. The results of studies of the Polish card will be provided - in terms of its adaptation to the needs of large families and the impact on the improvement of the situation, the family, and its relationship, both interfamilial and with local society. Finally, a model program — most fully meeting the needs of large families — will be proposed.

\section{Role, Situation, and Support for Large Families}

Although there is no single universal definition of a large family, the most common characteristic is that this is a family with at least three, or more rarely, four children. In this paper, the definition used by large family card implementers has been adopted as a family with at least three children.

The significance of large families in society is enormous. The family is the basic environment for the growth and development of a new generation. In families with many children (especially with large numbers of children), socialization runs differently than one or two children. The family is a natural environment in which children learn social skills such as: cooperation, responsibility, compassion, and concern for other human beings and making choices (Downey \& Condron, 2004).

However, the most important task of large families is the mitigating demographic crisis, especially in highly developed countries. Almost all European countries are struggling with a dramatically low rate of fertility, which in most of them remains below the replacement level (Organisation for Economic Co-operation 
and Development, 2011). What is more, those who have few siblings also tend to have few children themselves (Kravdal, 2010, p. 668), thus an increase in fertility within a generation that does not have many siblings is unlikely. Families with many children are therefore a unique group that decides to have another child, even at the cost of worsening their situation.

Having a large family in fact means resignation from a high standard of living and the need to reduce needs to a minimum. Despite these efforts, a significant part of such families falls into a group at risk of poverty, as "the more children, the lower the standard of living" (Bradshaw, Finch, Mayhew, Ritakallio, \& Skinner, 2006, p. 15). Large families are at very high risk of poverty in most European countries. In some, the risk is even higher than that in single parent families. Moreover, this risk is not associated with the unemployment of parents, as most often at least one of them works (Cantillon \& Van den Bosch, 2002). This problem has been indicated by many researchers dealing with issues of poverty, such as Redmond (2000) and Cantillon and Van den Bosch (2002). When adding to this the fact that on average, every third child is brought up in a large family, it seems necessary to support and ensure equal opportunities for their development.

Europe has one of the highest rates of expenditure on family benefits across the Organisation for Economic Co-operation and Development (OECD) countries (Lippman, Wilcox, \& Ryberg, 2014, p. 12). Most countries have a whole range of cash benefits, tax incentives, exemptions or deductions of charges, subsidies, and services in kind to support parents in raising children. Few of them, however, take into account the specific situation of families with many children (Wall, Pappamikaail, Leitao, \& Marinho, 2009). France, for example, promotes large families, whereas the United Kingdom promotes rather small ones. Finland gives the same support to all types of family (Bradshaw \& Finch, 2002).

Due to the relatively high family support in most European countries, the large family card is in fact a bonus rather than real support (except for less expensive utilities and public transport-lowering the cost of living). In Poland, however, where there is a lack of family policy, including families with many children, the Card is one of the key instruments for supporting large families. But even though this kind of support is mostly funded with public funds, it should be ensured that these funds are spent rationally and effectively. Support to families with many children should primarily support these families and therefore offer them products suited to their actual needs.

\section{Large Family Card in Europe}

The first large family card was created in France in 1921, where every year about 850,000 cards are issued. Similar solutions function in many other European countries, including Spain, Italy, Austria, Belgium, Luxembourg, Hungary, and Poland. Most large family cards are national programs, although regional (e.g., Austria) and urban (e.g., Italy) cards also exist. Polish large family cards operate as municipal programs (urban and rural) as well as in several counties; the government is also preparing a nationwide card. In most countries, the card is a government or local government program (e.g., France), although it may also be implemented by other entities, e.g., Non-Governmental Organizations (NGOs), as in Hungary.

In Spain, functioning of the card is governed at the national, regional, and local level. There is also a card issued by non-profit organizations. Discounts offered by the card consist of discounts on public transport, reduction in taxes (income, car, housing, local taxes), lower payments for water and energy, sport and leisure facilities, less expensive or free university, and discounts in more than 150 private companies (cards issued by NGO). 
In the Province of Rome, Italy, the card is only addressed to lower income families that also have two children, and elders (over 65 years). The card entitles them to discount on a range of food-type products, services, and entertainment, and the program involves more than 350 companies. In Hungary, in turn, an NGO called Nagycsaládosok Országos Egyesület (NOE) (National Association of Large Families) is responsible for card issuing and operating. The organization issues membership cards, i.e., tagsági kártya, entitling holders to discounts in various places as well as private companies taking part in the program all over the country (including zoos, theaters, etc.).

In France, the card is issued by SNCF (France's national state-owned railway company), and entitles families to a range of discounts and benefits, e.g., on public transport and rail fares, admission fees to museums, cinemas, sports facilities as well as discounts at more than 90 private companies (shops, restaurants, and services). Companies such as Auchan, C\&A, Intermarche, Novotel, and Yves Rocher have special offers for cardholders.

Research on the effectiveness of the card as a tool to support large families has not been widely carried out. In 2009, such a study was conducted in France and showed that families knew about the cards, although a much smaller number of them possessed or used such a card. What is more, the vast majority of cardholders mainly use the cards for discounts on rail travel, thus not knowing or barely using the program's other offers. Studies also indicate sources of information about the program, the effectiveness of information campaigns, and beneficiaries' opinions about the card. Studies have shown that, despite its long period of operation, general use of the card is still quite low.

Research conducted by the author aimed to show the influence of the large family card on quality of life in large Polish families. Due to the fact that most programs have only been launched in the last two years, a decision was made to choose to study only programs started from the end of 2011 (15 programs). The first section of questions concerned assessment of the impact of various areas of life to its quality, while the other - card usage and opinions is about the program. Areas of life, included in the questionnaire, have been limited to those whose support is possible through the large family card, and being participation in culture and leisure, educating children, the use of health protection system services, the threat of social exclusion, social attitudes and behavior, including social capital, social support, and to a certain extent the material situation of families. Figure 1 shows the assessment of respondents about the importance of different areas of life.

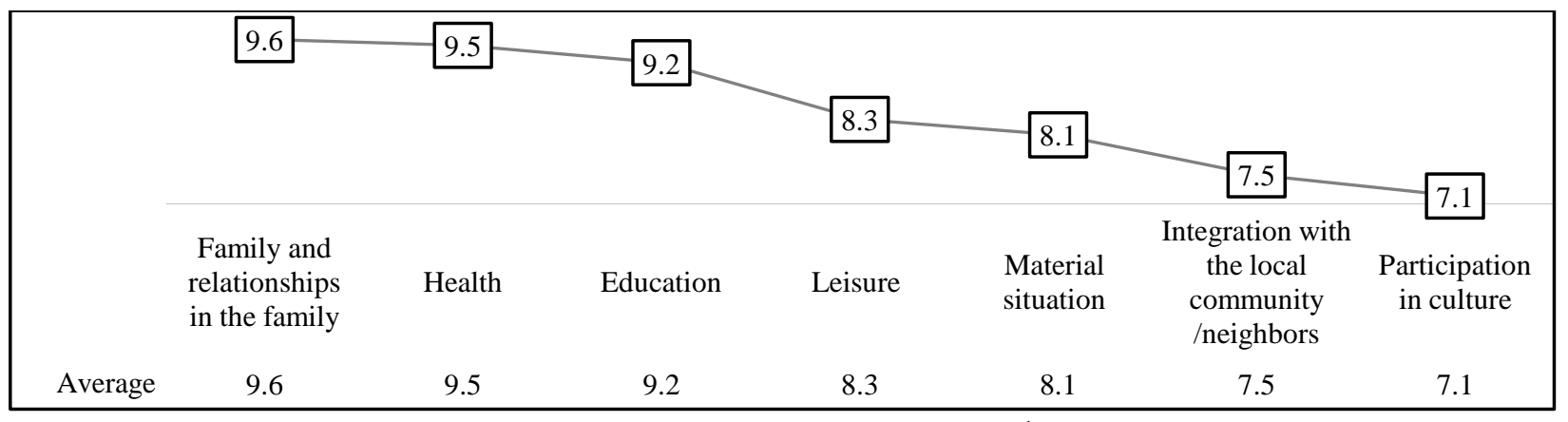

Figure 1. The importance of areas of life. ${ }^{1}$

Respondents who were asked about the most important aspects of their lives mainly pointed three of them - family, health, and education, with leisure and financial situation in the background. Integration with the

\footnotetext{
${ }^{1}$ Q: How important is a given sphere for the quality of life of your family (on a scale of 1 to 10$)$ ?
} 
community and participation in culture was evaluated at relatively low level.

Most programs focus their offer on varied leisure and cultural activities of the family. It should, however, be born in mind that educational and healthcare offers could be even more attractive for large families. In many cities, educational offers are provided by private companies, especially language schools

Respondents, who were asked about satisfaction with participation in the program and its impact on the family, expressed their satisfaction. Figure 2 and 3 show responses to questions about the level of satisfaction with participation in the program and its impact on the family. Nearly three in four respondents are satisfied or very satisfied with participation in the large family card program. A similar percentage believes that participation in the program had a rather favorable or strongly favorable influence on their family. The remaining respondents are mainly people who are partly satisfied, which, in fact, believe that the program has had no impact on their family. The number of people dissatisfied and those who believe that the program affected them negatively is marginal.

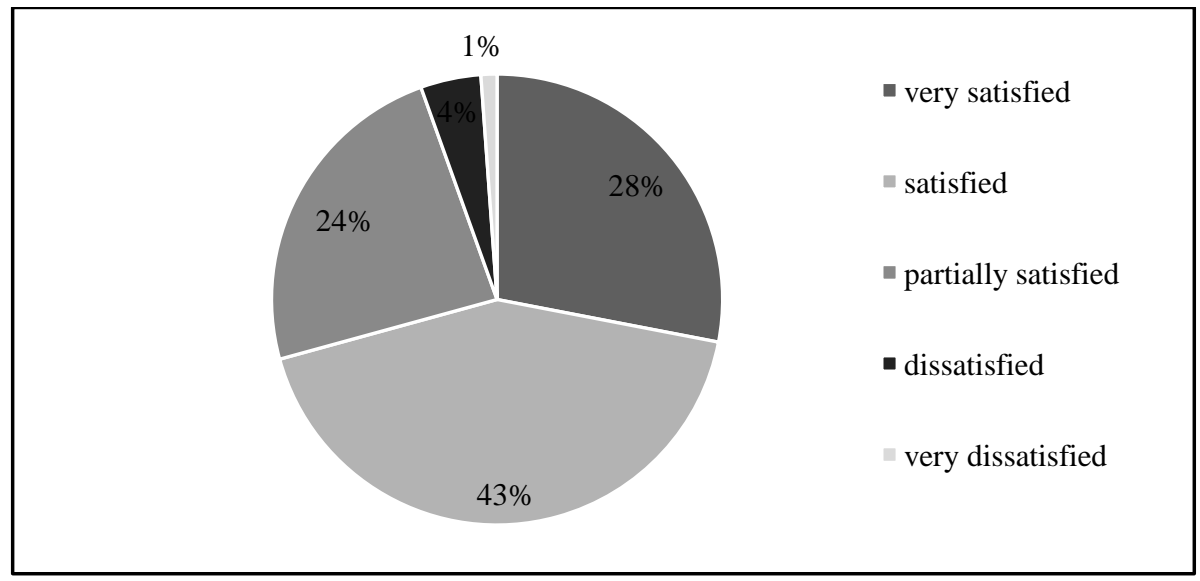

Figure 2. Satisfaction with participation in the program.

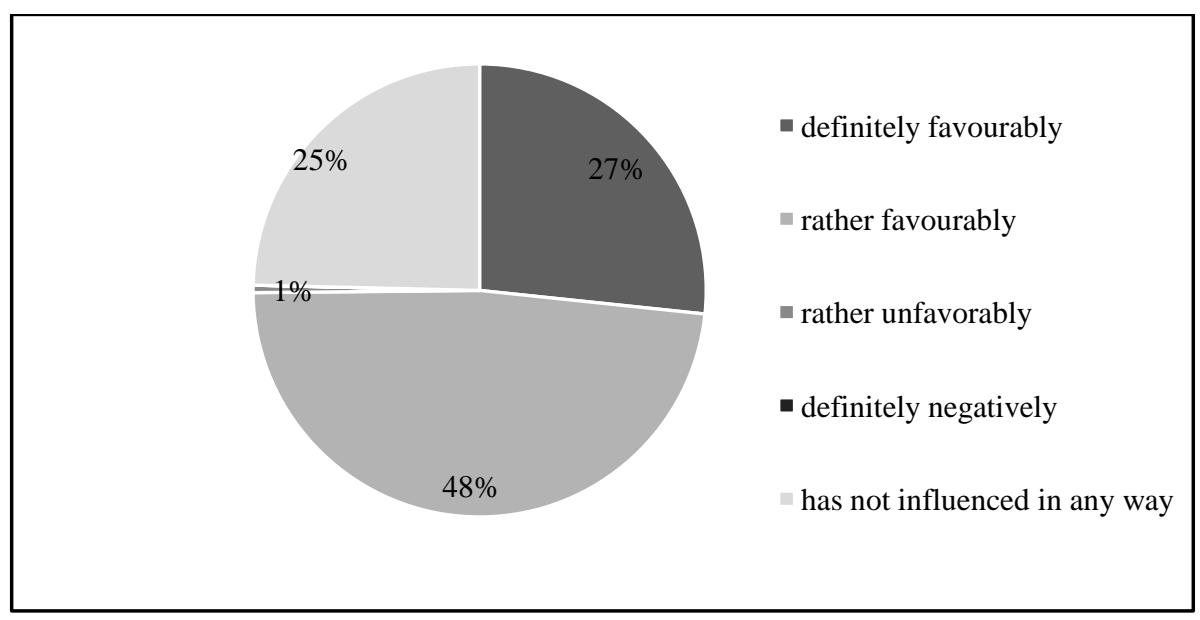

Figure 3. How participation in the program affects your family.

The situation is slightly different when asking about the actual use of the program offer. Respondents who were asked to specify the frequency of using the card (Figure 4), rarely pointed out the offer from which they would benefit at least once a week (mostly the swimming pool and public transport). What is more, in many cities, there are no healthcare services, cinemas, public transport, or even theater and museums within the offer. 
Other facilities are, in fact, not very attractive or varied, or still too expensive to use more often than a few times a year. The poor offer of the program is also confirmed by further questions. Figure 5 presents an assessment of the impact of the program on different areas of life.

There is a visible rather small effect of the card on health, education, economic situation of the family, and even change of attitude towards large families. Therefore, most of the purposes established by program implementers have not been so far achieved. Significant influence can be observed only in the field of leisure opportunities (this is the opinion of eight out of 10 respondents). Despite mixed feelings about the majority of the surveyed areas of life, nearly every respondent declared an interest in further participation in the program.

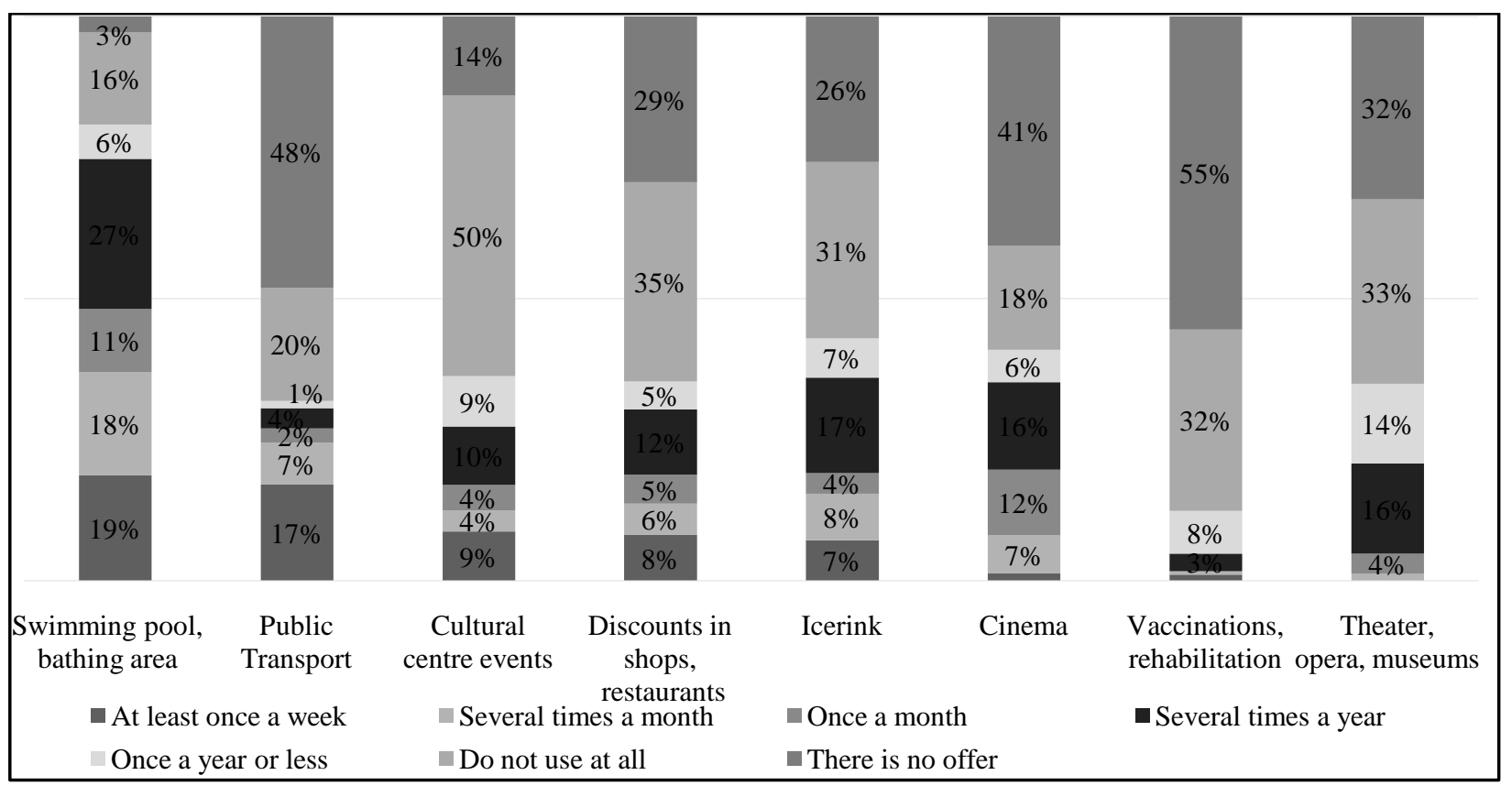

Figure 4. The frequency of using the offer. ${ }^{2}$

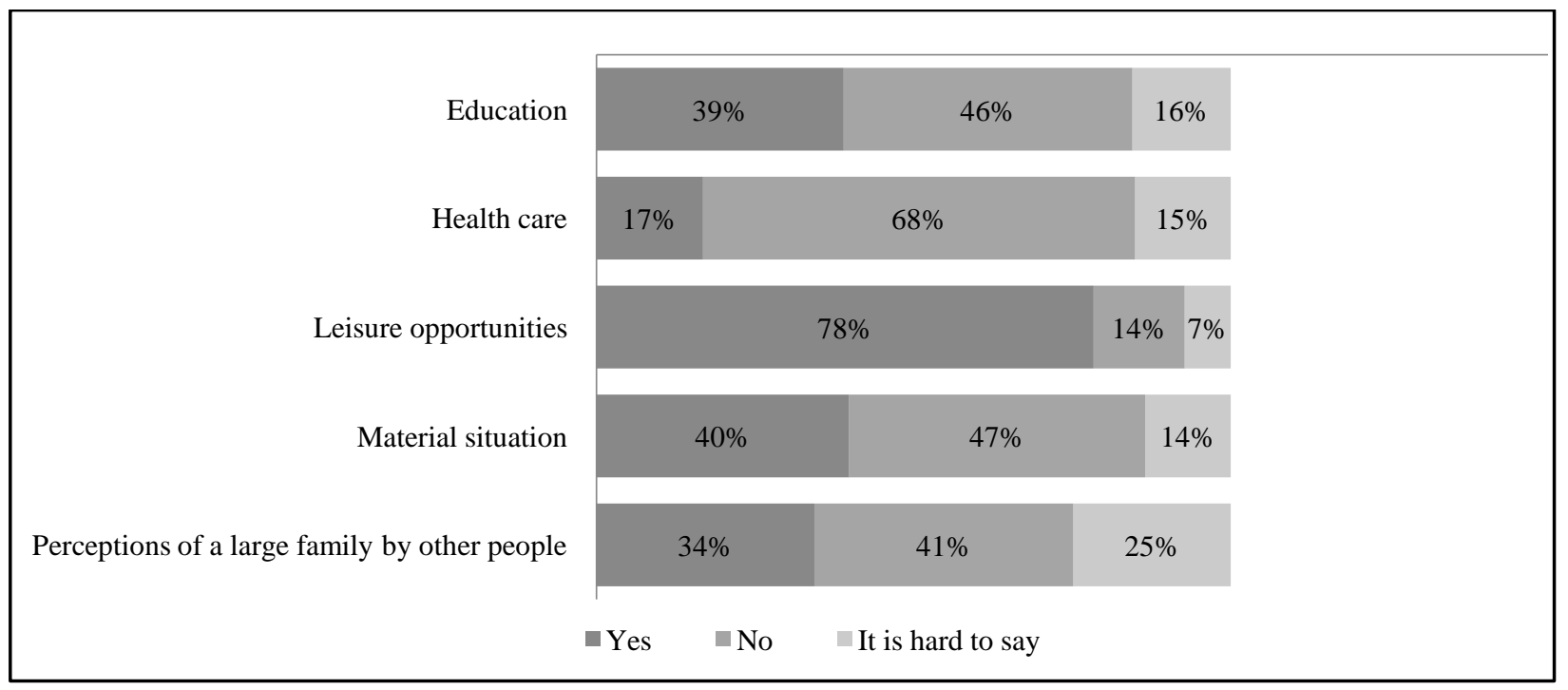

Figure 5. Chances and possibilities of the areas families have improved.

\footnotetext{
${ }^{2}$ Q: Which and how often do you and your family use offers within the program (if the offer is available)?
} 
The respondents are interested in almost every new offer of the program. All possible directions of its development have been rated very highly (Figure 6,7), although it can also be seen that there are some areas of less interest to large families.

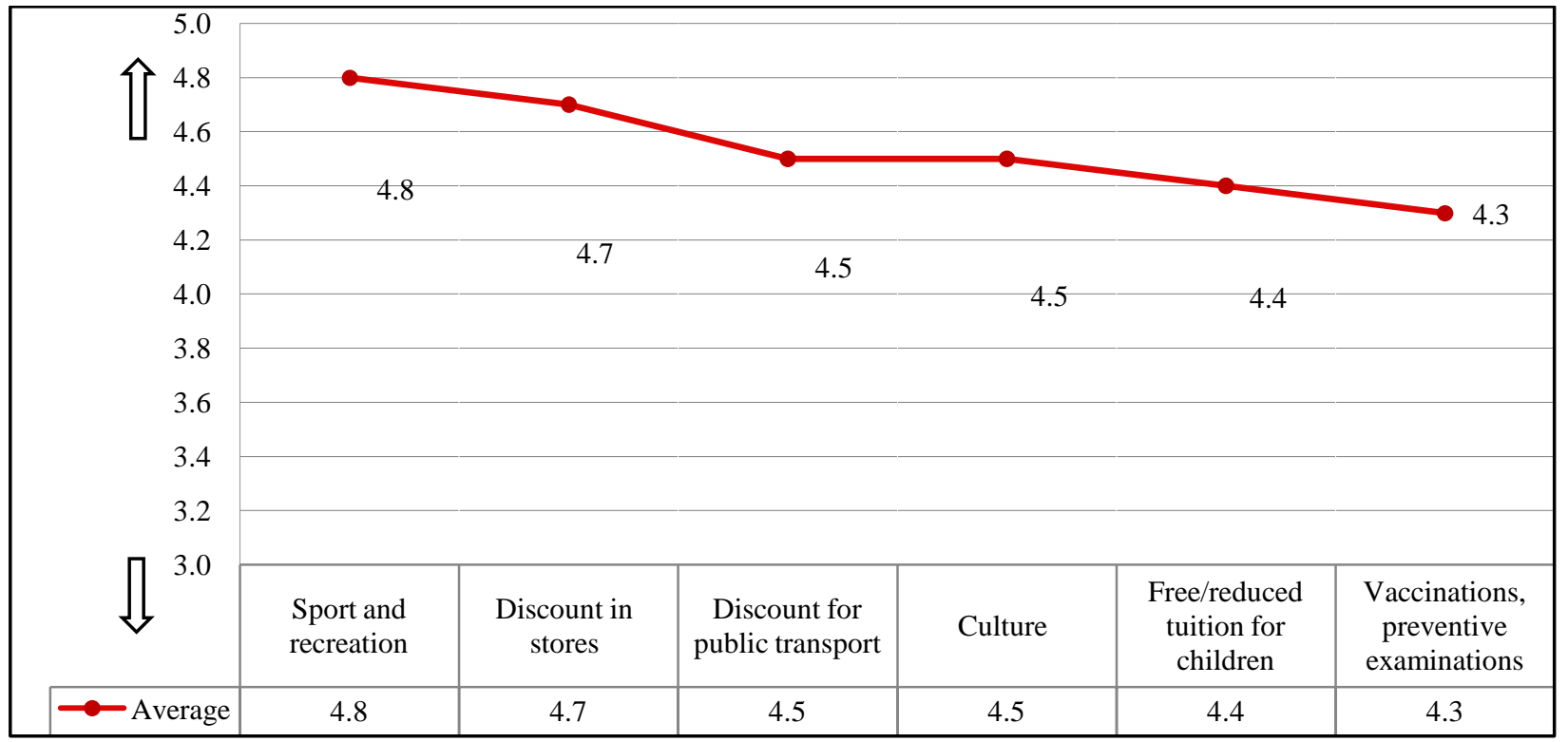

Figure 6. Willingness to use new offers (1).

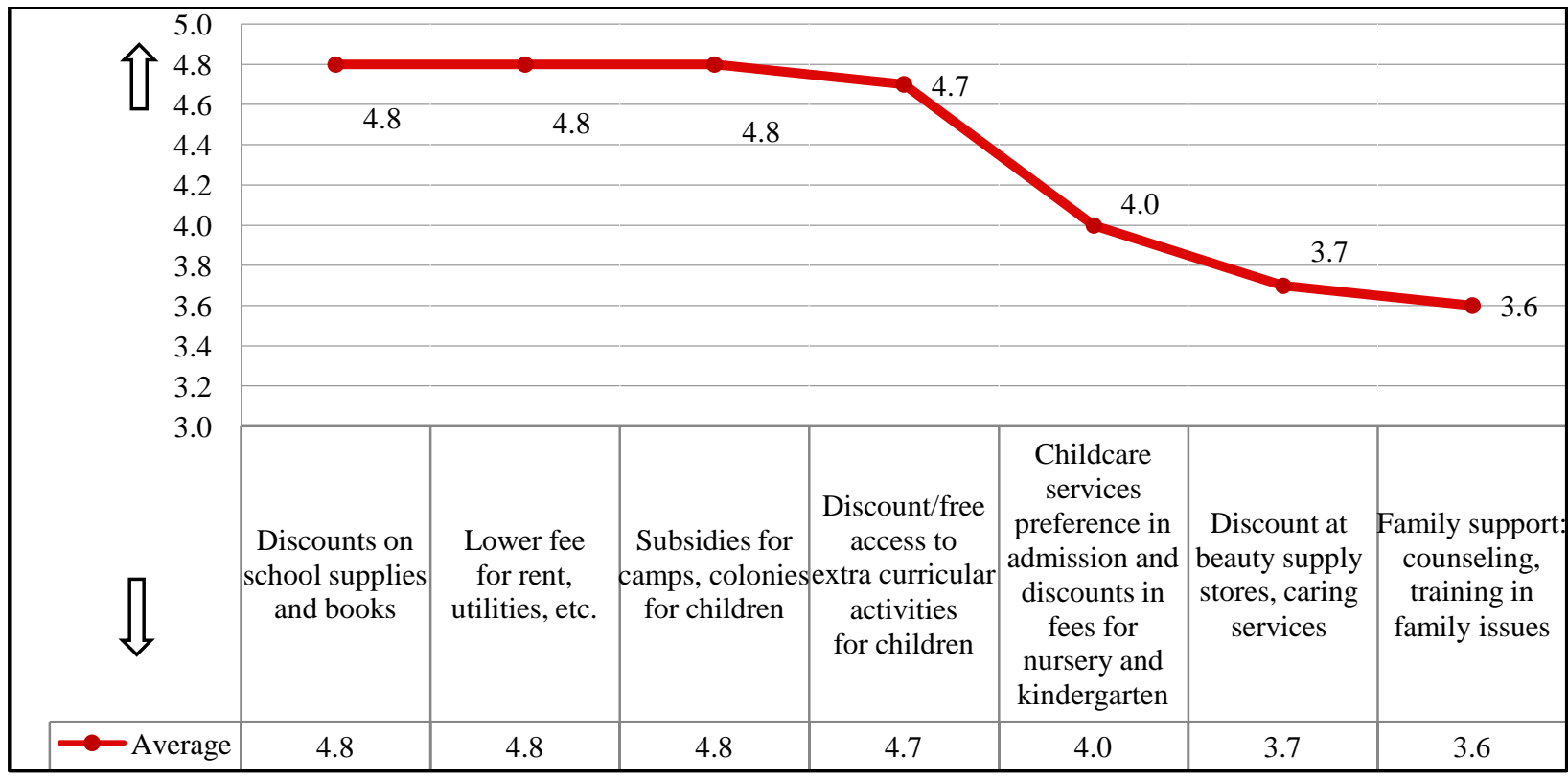

Figure 7. Willingness to use new offers (2). ${ }^{3}$

Respondents declared their willingness to use most of the potential offers and services that might be found in the new program offer. The most desirable ones are those that provide a better quality of life for their children and help with everyday expenses, such as payment for rent and utilities. Equally popular, and also the most popular so far, are cultural and sports offers.

\footnotetext{
${ }^{3}$ Q: How willingly would your family benefit from these offers/services if they were available in the program (on a scale of 1 to 5$)$ ?
} 
Large families are not especially interested in helping themselves through the greater availability of childcare facilities, family counseling, and discounts on luxury items, such as beauty salons, jewelers, etc.. In families with many children in Poland, very often one of the parents (the mother) stops working to take care of the offspring and home. Such families are also quite often assisted by grandparents. Thus, the offer in the form of institutional care for children is not of interest to parents. In turn, psychological and family counseling, available for free for large families, are associated with the solution to dysfunctional families and focus on solving selected problems (e.g., alcoholism). Well-functioning families do not want to be associated with this type of families, and therefore do not benefit from such assistance and are not interested in it. The lack of interest in luxury goods is undoubtedly related to the lack of financial means of large families and the rational use of their resources.

\section{Conclusions}

Although the large family card is (or should be) only an addition to the whole package of support for families with many children, it is perceived very positively by these families. This assessment seems somewhat exaggerated after examination of the offer and its actual use by families. Apart from its positive impact on the diversification of sports and recreation activities, it does not basically play any role in supporting the condition of the family. Neither healthcare nor the educational aspect is attractive enough to interest the family. The basic reason for the low quality of programs is primarily the lack of proper communication and knowledge about the real problems affecting large families. In fact, statements (there is a lack of communication between program coordinators and recipients. Our expectations and needs are examined in a poor way, or no one asks us whether we are satisfied or not. There is virtually no contact between us and the office. We do not know to whom and how to convey our needs and comments) have been heard many times in FGIs.

The solution to the problem identified above, which is used in certain cities, is inclusion into the program of non-profit organizations, representing the interests of families. Thus, there is a chance to properly understand the needs and adapt the offer to the recipients. Among the 15 programs examined, just five declared any cooperation with NGOs, and only two of them were this cooperation stable and successful (these programs received the highest ratings of respondents).

Among the features that should be implemented in a good program and which should, in particular, be indicated are: good information flow between implementers and families, competent staff to operate the program to build a positive image of large families, an offer matched to children of all ages, a healthcare extension, an educational and public transport (in big cities) offer, an offer by private companies intentionally selected and negotiated, appropriate promotion of the program.

\section{References}

Bradshaw, J., \& Finch, N. (2002). A comparison of child benefit packages in 22 countries. Retrieved from: http://www.dwp.gov.uk/asd/asd5/rrep174.asp/

Bradshaw, J., Finch, N., Mayhew, E., Ritakallio, V., \& Skinner, C. (2006). Child poverty in large families. Retrieved from: http://eprints.whiterose.ac.uk/73203/1/Document.pdf

Cantillon, B., \& Van den Bosch, K. (2002). Social policy strategies to combat income poverty of children and families in Europe. Retrieved from: http://hdl.handle.net/10419/95412

Downey, D. B., \& Condron, D. J. (2004). Playing well with others in kindergarten: The benefit of siblings at home. Journal of Marriage and Family, 66(2), 333-350. 
Kravdal, Ø. (2010). Demographers' interest in fertility trends and determinants in developed countries: Is it warranted? Retrieved from: http://www.demographic-research.org/Volumes/Vol22/22/ DOI: 10.4054/DemRes.2010.22.22

Lippman, L., Wilcox, W., \& Ryberg, R. (2014). World family indicators. Retrieved from http://www.lisdatacenter.org/wps/liswps/612.pdf

Organisation for Economic Co-operation and Development. (2011). Doing better for families. Retrieved from http://www.oecd.org/social/family/doingbetter/

Ostasiewicz, W. (2002). Metodologia pomiaru jakości życia (Methodology of measuring the quality of life). Wrocław: AE we Wrocławiu (Wroclaw University of Economics).

Redmond, G. (2000). Children in large families: Disadvantaged or just different? Retrieved from http://www.lisproject.org/publications/liswps/225.pdf/

Wall, K., Pappamikaail, L., Leitao, M., \& Marinho, S. (2009). Council of Europe family policy questionnaire. Retrieved from http://www.leavenetwork.org/fileadmin/Leavenetwork/Links_publications/Family_Policy_in_Council_of_Europe_member_ states_en.pdf 